\title{
The relationship between issues related to occupational attachment of nurses in health and medical centers of Estahban City
}

\author{
Dariush Ranjbar ${ }^{1}$, Abbas Yazdanpanah",", Ali Khani Jeihooni ${ }^{3}$
}

${ }^{1}$ PG Student, ${ }^{2,3}$ Assistant Professor, ${ }^{1,2}$ Dept. of Healthcare Management, Marvdasht Branch, Islamic Azad University, Marvdasht, Iran, ${ }^{3}$ Department of Public Health. School of Health, Fasa University of Medical Sciences, Fasa, Iran

\section{*Corresponding Author:}

Email: abbas_yaz@miau.ac.ir

\begin{abstract}
Purpose: Occupational attachment is one of the variables that can be seen by the employees in creating positive consequences for the organization. Career-minded employees form spiritual relationships with their jobs and invest specific resources in their current jobs, and this is one of the important factors in the lives of individuals. The individual's attitude toward his work reflects a negative or positive evaluation that he has in relation to an aspect of his work environment. Among various job attitudes, attachment to a job is a measure that a person likes to match with his job or the extent to which the occupation of the person's identity center is of particular importance.

Materials and Methods: The research method is applied in terms of purpose and descriptive-applied method. Correlation method has been used. The research sample was 145 nurses of the hospital and health centers of Estahban city who were selected by available sampling method. To evaluate the variables, two questionnaires were used by researcher and occupational attachment questionnaire. Data analysis was done using descriptive statistics using spss software.

Results: There is a significant positive relationship between personal factors with occupational attachment $(226 / \mathrm{r}=\mathrm{r})$. The higher the individual factors of the nurses, the higher the level of job attachment. There is a significant positive relationship between economic factors with occupational attachment $(212.0 \mathrm{r}=)$. The higher the economic factors of nurses, the higher the job attachment. There is a significant positive relationship between organizational factors with occupational attachment $(\mathrm{r}=.231)$. The higher the organizational factors in nurses, the higher the level of occupational attachment. There is a significant positive relationship between environmental factors with occupational attachment $(r=.249)$. The higher the nurses' environmental factors, the higher the level of occupational attachment.

Conclusion: Therefore, nurses' attachment to their jobs is one of the most important research topics in the field of health systems, since in many countries nurses form one of the largest groups of health professionals. Therefore, the nature and quality of services provided to Patients are highly dependent on their function.
\end{abstract}

Keywords: occupational attachment, Individual factors, Economic factors, Organizational factors, Environmental factors.

\section{Introduction}

Nurses as the biggest human resources of health and medical organization, have rightful importance in growing society's health; as health and medical organization without beneficial nursing power cannot achieve any success. ${ }^{1}$ Longtime working shifts, more than one working shift of staffs, wanted and unwanted overtimes, all are items that effect on occupational consent of nurses. ${ }^{2}$ Lack of occupational consent also can effect negatively on the way of nurses care related to patients, thus by decreasing the quality of care likely causes longtime residence of patients in hospital and increasing negative social, economical and psychological effects due to lack of health and health care. ${ }^{3}$ One of the issues that can greatly overshadow occupational consent and function on itself, is occupational attachment. Occupational attachment is one of the variables that by creating it in staffs, positive outcomes for the organization can be seen. The first researches on this area are related to the investigations of Kanungu (1982). Staffs attached to job, shape spiritual relations to their jobs and invest specific resources on their current jobs and it is one of the important factors in working life of people. ${ }^{4}$ Occupational attachment defines the intensity of psychological imitation of a person to his/her job. ${ }^{5}$ Occupational attachment also was defined as determining spiritual identity of staffs with their current jobs. ${ }^{6}$ Occupational attachment causes growth in occupational attachment and client's consent, profitmaking and productivity. ${ }^{7}$ For an employee, attachment to work is an inseparable section of his/her personality. ${ }^{8}$

Occupational attachment is a fundamental agent in lives of frequently of people. Employees in occupational environment mentally and excitatory are affected by the amount of their attachment to their jobs. ${ }^{9}$ Some of the researchers believe that occupational attachment mostly is affected by internal and personal factors. Oppositely, some believe that occupational attachment can also be affected by externalorganizational factors. ${ }^{6}$ People attached to job, tend to have strong emotional connections with the organization and it causes for them to think less about leaving the organization than other people. ${ }^{10}$

Employees attached to job also have lots of energies and have sufficient enthusiasms for performing their occupational obligations. They concentrate and float on their works in such a way that do not understand passing time. ${ }^{11}$ 
The aim of doing this research is determining the relation between factors related to occupational attachment of nurses in health and medical centers of Estahban city.

\section{Review of literature}

In an article as the relationship between spiritual leadership and realized organizational support with occupational fatigues of nurses by Asgari Mobarake and Karimi (2017), they concluded that there are meaningful and converse relations between spiritual leadership and landscape variables, faith to work, membership, organizational obligation and realized organizational support with occupational fatigues and productivity of spiritual leadership is not meaningful with occupational fatigue. The best predictor of occupational fatigue was organizational support. ${ }^{12}$ Soudani and colleagues (2016) in a research as simple and multiple relation of personal and organizational variables with occupational attachment in nurses concluded that aspects of organizational justice, objectivism and sense of duty can predict changes related to occupational attachment testable items. Among the aspects of organizational justice, just superficial justice could predict objectivism and aspects of distributive justice and superficial justice could forecast sense of duty of nurses. Findings also showed that $32 \%$ of variance of attachment related to testable issues were explained by means of personal features of objectivism and sense of duty and aspects of organizational justice. ${ }^{13}$ In a research as investigation of the relation related to quality of working life, organizational atmosphere and realized organizational support with occupational attachment of nurses in Bagheral Oloum hospital of Ahar city, Pour Ghasem(2015) concluded that there is a positive and direct relation between quality of working life with occupational attachment, organizational atmosphere with organizational attachment and realized organizational support with occupational attachment in level of $0.01 .{ }^{14}$ Bobbio and colleagues(2012) in a research as empowerment of leadership, realized organizational support, reliance with occupational fatigue of nurses in public hospital of Italy concluded that reliance of leader on organization and realized organizational support have negative effects on occupational fatigue of nurses and also fundamental role of trust has been verified in health care organizations. ${ }^{15}$

Cho and colleagues (2011) state in their research that the relation between occupational attachment of Canadian newly graduated nurses has been with their organizational obligations. ${ }^{16}$ Stander and Rothmann(2010) believe that employees who have more skills and abilities for performing their actions, have more attachment to their works. ${ }^{17}$ Laschinger and colleagues(2011) found in their research that justice has relation with occupational attachment of nurses. ${ }^{18}$
Hypotheses of the research are as follow:

Hypothesis 1: There is a relationship between personal factors with occupational attachment in health and medical centers of Estahban city.

Hypothesis 2: There is a relationship between economic factors with occupational attachment in health and medical centers of Estahban city.

Hypothesis 3: There is a relationship between organizational factors with occupational attachment in health and medical centers of Estahban city.

Hypothesis 4: There is a relationship between environmental factors with occupational attachment in health and medical centers of Estahban city.

\section{Materials and Methods}

This study is a descriptive investigation related to correlation. Statistical population of this research is all nurses in hospital and rural and urban health and medical centers that are 300 and were investigated by available sampling. On the basis Morgan table, sample size of 169 was investigated and 24 questionnaires were omitted from sample population because of being incorrect and not answering by nurses and only 145 questionnaires were investigated as statistical samples.

\section{Research material}

In this study for gathering data, questionnaire is used. Questionnaires comprise: Occupational attachment questionnaire and a questionnaire by the researcher.

\section{Occupational attachment questionnaire}

This questionnaire has been prepared by Edward Zvkyl Patrick in 1984 and has 20 items. The way of scoring it is on the basis of a 4 grade scale, as in positive items of $1,2,3,4,5,6,7,8,9,12,15,20$ numbers of $3,2,1,0$ are belonged to strongly disagree, disagree, agree and strongly agree, respectively and in negative items of $(10,11,13,14,16,17,18,19)$ the point belongs adversely, it means that $0,1,2,3$ are belonged to strongly disagree, disagree, agree and strongly agree, respectively. Maximum point of 60 represents really high attachment and minimum point of (0) shows really low attachment.

Pourtorab(2011) for determining reliability, two methods of Cronbach's alpha and bisection were used and are respectively 0.83 and 0.84 that represent desirable coefficients of reliability of mentioned questionnaire. For determining the reliability of questionnaire also its point was correlated with questionnaire of occupational satisfaction and it was specified that there is a positive meaningful relation between their scores and represents that questionnaire of occupational attachment has essential reliability. ${ }^{19}$ In investigation of Soudani and colleagues (2017), coefficients of internal similarity were achieved 0.81 by Cronbach's alpha of the questionnaire. 
Findings of the study

Hypothesis 1. There is a relationship between personal factors with occupational attachment in health and medical centers of Estahban city.

Table 1: Correlation coefficient of personal factors with occupational attachment

\begin{tabular}{|l|c|c|}
\hline \multicolumn{1}{|c|}{ Variable } & $\mathbf{r}$ & $\begin{array}{c}\text { Sig(meaningful } \\
\text { level) }\end{array}$ \\
\cline { 1 - 1 } Personal factors & 1226 & 0.006 \\
\cline { 1 - 2 } $\begin{array}{l}\text { Occupational } \\
\text { attachment }\end{array}$ & 0 & \\
\hline
\end{tabular}

According to table 1 , it can be realized that there is a positive meaningful relationship in level of 0.01 between personal factors with occupational attachment. When personal factors of nurses are high, the amount of occupational attachment will be also higher.

Hypothesis 2. There is a relationship between economic factors with occupational attachment in health and medical centers of Estahban city.

Table 2: Correlation coefficient of economic factors with occupational attachment

\begin{tabular}{|l|c|c|}
\hline \multicolumn{1}{|c|}{ Variable } & $\mathbf{r}$ & $\begin{array}{c}\text { Sig(meaningful } \\
\text { level) }\end{array}$ \\
\hline $\begin{array}{l}\text { Economic } \\
\text { factors }\end{array}$ & 1212 & 0.01 \\
\cline { 1 - 1 } $\begin{array}{l}\text { Occupational } \\
\text { attachment }\end{array}$ & 0 & \\
\hline
\end{tabular}

According to table 2, it can be realized that there is a positive meaningful relationship in level of 0.01 between economic factors with occupational attachment. When economic factors of nurses are high, the amount of occupational attachment will be also higher.

Hypothesis 3. There is a relationship between organizational factors with occupational attachment in health and medical centers of Estahban city.

Table 3: Correlation coefficient of organizational factors with occupational attachment

\begin{tabular}{|l|c|c|}
\hline \multicolumn{1}{|c|}{ Variable } & $\mathbf{r}$ & $\begin{array}{c}\text { Sig(meaningful } \\
\text { level) }\end{array}$ \\
\cline { 1 - 1 } $\begin{array}{l}\text { Organizational } \\
\text { factors }\end{array}$ & $/ 231$ & 0.005 \\
\cline { 1 - 1 } $\begin{array}{l}\text { Occupational } \\
\text { attachment }\end{array}$ & 0 & \\
\hline
\end{tabular}

According to table 3, it can be realized that there is a positive meaningful relationship in level of 0.01 between organizational factors with occupational attachment. When organizational factors of nurses are high, the amount of occupational attachment will be also higher.
Hypothesis 4. There is a relationship between environmental factors with occupational attachment in health and medical centers of Estahban city.

Table 4: Correlation coefficient of environmental factors with occupational attachment

\begin{tabular}{|l|c|c|}
\hline \multicolumn{1}{|c|}{ Variable } & $\mathbf{r}$ & $\begin{array}{c}\text { Sig(meaningful } \\
\text { level) }\end{array}$ \\
\cline { 1 - 1 } $\begin{array}{l}\text { environmental } \\
\text { factors }\end{array}$ & $/ 231$ & 0.005 \\
\cline { 1 - 1 } $\begin{array}{l}\text { Occupational } \\
\text { attachment }\end{array}$ & 0 & \\
\hline
\end{tabular}

According to table 4, it can be realized that there is a positive meaningful relationship in level of 0.01 between environment factors with occupational attachment. When environmental factors of nurses are high, the amount of occupational attachment will be also higher.

\section{Discussion and Conclusion}

The results of table 1 showed that there is a relationship between personal factors with occupational attachment in health and medical centers of Estahban city. The results of this hypothesis are favorable and consonant with results of Fattah Beigi (2014).

In explaining this hypothesis it can be stated that occupational attachment effects on person and also organization. From organizational point of view, occupational organization has been regarded as a key for opening the motivation of employee and increasing production and from personal view, is regarded as a key for motivation of function and personal growth and satisfaction in workplace. Occupational attachment by involving employees deeply in their works and making meaningful restoration work, helps in organizational effectiveness, production and employee mentality. ${ }^{20}$

When personal factors of nurses are high, their occupational attachment will be also higher, obviously people with high occupational attachment are satisfied with their jobs, have positive mentality in works and represent high obligation than organization and their colleagues. They rarely think about withdrawal of job and it is expected that they work for their obeyed organization for years.

The results of table 2 showed that there is a relationship between economic factors with occupational attachment in health and medical centers of Estahban city. The results of this hypothesis are favorable and consonant with results of Asefi Yegan Mahalle (2015).

Economic factor has crucial role in occupational attachment of nurses. Researches of Luck show that salaries and fees are determining factors in occupational satisfaction and attachment. Especially when from employee's point of view, this payment is fairly and rightly. Advancements comprise positive change in salaries (higher salaries), growth and placing in 
supervision, more working challenge, more obligation and freedom in decision-making. Because of this issue that growth represents the amount of person's value for the organization (especially in more superior levels), person's advancement leads to growth in his/her mentality.

According to the model of demand-control, lack of balance between demands and posed requests in job and the amount of person's control on his/her work are factors that create stress, while the model of effortreward emphasizes on job's conditions and also employed person and lack of balance between high effort and low reward have been factors that create stress. Totally, these two models can greatly represent psychological stresses due to job that lead to disorder in health. $^{21}$

The results of table 3 showed that there is a relationship between organizational factors with occupational attachment in health and medical centers of Estahban city.

The results of this hypothesis are favorable and consonant with results of Keshtkaran and colleagues (2018), Zarifi and colleagues (2013), Farahmandi and colleagues(2018), Cho and colleagues(2006), Laschinger and colleagues(2006), Taghi Pour and Khadem Dezfouli(2013). Organizational factors are the first and main effective factors on occupational attachment of staffs. Occupational attachment has led to positive attitudes and motivation toward organization, because staffs attached to job frequently experience feelings such as happiness, enjoy and satisfaction and these experiences have led them to being faithful to organization that are working on it. Nurses attached to job, have introduced themselves to the organization that are working in it. People attached to work have positive attitudes about their jobs, because spend lots of energies for doing obligations and assign noticeable time to their occupational activities and as occupational satisfaction represents total attitude of person about his/her work. So, nurses attached to work because of really positive attitudes toward their works, have high level of occupational satisfaction. It seems that fairly behavior of the organization toward nurses increases their feeling of occupational security and growth in their energies causes hospital's success in the field of servicing to the patients.

The results of table 4 showed that there is a relationship between environmental factors with occupational attachment in health and medical centers of Estahban city. The results of this hypothesis are favorable and consonant with results of Keshtkaran and colleagues (2018).

In expressing these findings it can be said that environmental factors of work also have especial importance in increasing occupational attachment of staffs. Wherever supervisors have had supportive and friendly behavior with staffs, occupational attachment has been also high. When occupational conditions are more proper, they cause occupational satisfaction and attachment. Because in proper working conditions, better physical and mental calmness will be prepared for person.

Finally, it is suggested that responsible people and managers of the hospital and health and medical centers that are studied, policy and support of effective factors on occupational attachment and cooperation with researchers and scholars in more studying and investigations, prepare necessary bed for creating them among nurses.

\section{References}

1. Nabizadeh Gharghozar Z, AtashzadehShoorideh F, Khazaei N, Alavi-Majd H. Assessing organizational commitment in clinical nurses. Iranian Journal of Nursing Vision. 2013;2(2):41-8.[Persian].

2. Mirzabeigi G, Salemi S, Sanjari M, Shirazi F, Heidari S, Maleki S. Job satisfaction among Iranian Nurses. Hayat. 2009;15(1):49-59. [Persian].

3. Movahhed M, Moghaddam Y. Survey of job satisfaction and the factors affecting it, with employed nurses in the educational and curative centers of Uromieh University of Medical Sciences. Journal of Nursing and midwifery Uromieh University of Medical Sciences. 2005;2(2):1-10. [Persian].

4. Rotenberry P. Mediating the impact of job involvement on organizational outcomes: The role of supervisorfocused commitment. [Phdthesis] Management Psychology, Ohio: the University of Akron, 2003.

5. Mahdad A. Industrial and Organizational Psychology. Isfahan: Jangal publisher. 2013. [Persian].

6. Azizi $\mathrm{H}$. The effect of organizational justice and job characteristics on job involvement in the organization of Islamic Republic of Iran Customs. [MSc.thesis] management. Tehran: Payam-A- Noor University of Tehran. 2011. [Persian]

7. Emery C, Barker K. Effect of commitment, job involvement and teams on customer satisfaction and profit. Team Performance Management, Learning and Pedagogy. 2007; 13(3- 4): 90-101.

8. Rotenberry PF, Moberg PJ. Assessing the impact of job involvement on performance. Manag Res News2007;30:203-15.

9. Word J, Park SM. Working across the divide job involvement in the public and nonprofit sectors. Review of Public Personnel Administration. 2009;29(2):103-33.

10. Hallberg, U. \& Schaufeli,W.B. (2006). "Same Same" but different? Can work engagement be discriminated from job involvement and organizational commitment? European Psychologist, 11,119-27.

11. Schaufeli, W.; Salanova, M.; González-Romá, V.; Bakker, A. (2002). "The measurem42ent of engagement and burnout: A two sample confirmatory factor analytic approach". Journal of Happiness studies, 3(1),71-92.

12. Asgari Mobarake, Amin and Karimi, Fariba.(2017). The relationship of realized spiritual leadership and organizational support with occupational fatigue of nurses. Journal of nursing research of Iran. Volume 11, number 5 .

13. Soudani, Miase; Mostafavi Rad, Fereshte; Chin Ah, Mahboube.(2016). Simple and multiple relationship of personal and organizational variables with occupational attachment in nurses. Nursing management. Course 4. Number 3. 
14. Pour Ghasem, Sedighe. (2015). Investigation of the relationship between quality of working life, felt organizational atmosphere and organizational support with occupational attachment of nurses in hospital of Bagher Aloloum in Ahar city. Master thesis. Oroumie University.

15. Bobbio A, Bellan M, Manganelli AM. Empowering leadership, perceived organizational support, trust, and job burnout for nurses: a study in an Italian general hospital. Health Care Manage Rev. 2012;37(1):77-87. DOI: 10.1097/HMR.0b013e31822242b2 PMID: 21743337.

16. Cho J, Laschinger HK \& Wong C. Workplace empowerment, work engagement and organizational commitment of new graduate nurses. Nursing Leadership 2011 Sep;19(3):43-60.

17. Stander, M. W.; Rothmann, S. (2010). "Psychological empowerment, job insecurity, and employee engagement. SA Journal of Industrial Psychology. 36(1),1-8.

18. Laschinger HK, Wong CA \& Greco P. The Impact of Staff Nurse Empowerment on Person-Job Fit and Work Engagement/Burnout. Nurs Admin Q 2011;30(4):358-67.

19. Asgari P, Pourtorab H. Relationship between quality of working life, job involvement and organizational health and employee commitment of the National Bank of Ahvaz. New findings in the Journal of Psychology. 2010;2(4):7-18. [Persian].

20. Boon, O. K., Arumugam, V., Safa, M.S., \& Bakar, N.A. (2007). HRM AND TQM: association with job involvement.Personnel Review, 36, 939-62.

21. Bazr Afkan, Hesam; Hashemi Sheikh Shabani, Seyed Esmaeil; Arshadi, Nasrin. (2012). Structural analysis related to conflict of work-family with occupational satisfaction and mental health. Quarterly of consultation and psychology of family. First year. Number 3. 